\title{
Building a foundation for utilizing evidence based practice in conjunction with research in baccalaureate nursing program
}

\author{
Young-Shin Lee, Carmen Galang, Janet E. Hughen \\ School of Nursing, San Diego State University, San Diego, California, USA
}

Received: May 2, 2020

DOI: $10.5430 /$ jnep.v10n10p1

\author{
Accepted: June 12, 2020 \\ Online Published: June 18, 2020 \\ URL: https://doi.org/10.5430/jnep.v10n10p1
}

\begin{abstract}
Less is known about the undergraduate nursing students' ability to conduct beginning research. This study aims to explore and describe nursing students' experiences in planning and implementation of community health fairs; and utilizing evidence based practice integrated with research as a learning outcome. The study using a quantitative and descriptive design was conducted by senior nursing students during diverse community health events as a part of Gerontological nursing clinical. The students utilized three fall assessment tools: Balance and Gait test, Timed Up and Go test, and 10-year Fracture Risk Calculation. A total of 74 students participated in seven community health fair events focused on Fall Prevention. This health fair event was in conjunction with the National Fall Prevention Awareness week. A total of 201 older adults were served during the event by nursing students who provided screening process and related health education. Data were gathered and a group of students volunteered to complete the research process. The students participated in oral presentation in the Annual University Research Student Symposium and had poster presentation in the professional academic conference. Early systematic organized planning of the clinical experience gives students opportunity to integrate evidence based practice into research. Application of varied evidence based assessment tools focused on older adults enables students to understand the health issue in depth and the need for additional services. Health fair experiences improve students' communication and education skills, reality of health issues of the target population in a community, and evidence based research.
\end{abstract}

Key Words: EBP, Health fair, Research, Gerontology, Baccalaureate nursing

\section{BACKGROUND}

Nurses at all levels should develop research skills for the continual development of a relevant body of knowledge. The spirit of inquiry is acquired in undergraduate education and the characteristics of a fundamental nurse researcher are also initially developed in the lower level of nursing education. ${ }^{[1]}$ Students' knowledge of evidence-based practice (EBP) is important to improve health care outcomes. ${ }^{[2,3]}$ Integrat- ing research and EBP and clinical course services create an avenue to enhance quality care and patient outcomes.

Benefits and outcomes of undergraduate participation in research are documented. ${ }^{[4-7]}$ Although undergraduate nursing students have positive attitudes toward using research for evidence-based practice, ${ }^{[8]}$ nursing students as compared to those in other disciplines do not have enough opportunity to explore and integrate research. ${ }^{[9]}$

${ }^{*}$ Correspondence: Young-Shin Lee; Email: ylee@sdsu.edu; Address: School of Nursing, San Diego State University, San Diego, 5500 Campanile Dr., San Diego, California, USA. 
While the benefits of undergraduate students' research participation are essential, integration of research and clinical practice in undergraduate education seems to be a challenge in current baccalaureate nursing curriculum. Deterrent factors reported include lack of support and opportunity for research, time involved in research process, other didactic and clinical courses, and lack of faculty members to mentor for students who show interest in beginning research. ${ }^{[5,8]}$

Regarding the integration of clinical practice and research experience in Baccalaureate nursing programs, several nursing organizations provide suggestions as: 1) The Essentials of Baccalaureate Education for Professional Nursing Practice note that students should be encouraged to participate in research studies that investigate issues focusing on care of older adults, $\left.{ }^{[10]} 2\right)$ Students should be provided research opportunities (Council on Undergraduate Research (COUR) ${ }^{[11]}$ and 3) Recommended Baccalaureate Competencies guide nursing students to have opportunities to practice their competencies through health fairs occurring in the community. ${ }^{[12]}$

In fact, studies have shown that providing health screenings and education in community participatory events were effective methods to gain knowledge and health outcomes. ${ }^{[13-16]}$ When students provide services during health fairs, students are able to acquire evidence based research information as learning outcomes $(8,16)$. These experiences involving the university and the local community are beneficial not only to students but also to participants of various community event settings.

This study adopted a three-stage model for practical reflection, which consists of: curiosity, "looking closer" through the examination of actual learned information, and transformation. ${ }^{[17]}$ The model explains the following: (1) Curiosity: At the curiosity level, students show their curiosity to use their knowledge and skills in a health fair through participation in the event. (2) Looking Closer: Students examine the reality of health conditions of people in the community through their service with nursing skills, knowledge, counseling, and education, which comprise the stage of "looking closer" and obtaining information through questions and answers regarding pertinent health topics. Students assess participants' fundamental health problems by measuring vital signs, evaluating nutrition habits, and identifying healthy and non-healthy behaviors regarding chronic health problems. (3) Transformation: Following the health fair, students will clarify the health issues by gathering, analyzing, and synthesizing the information. Students apply their knowledge of research and obtain information about the results of their service to transform their nursing behaviors. Through this process, students integrate their previously learned knowl- edge on selected health problems and analyze health related data gathered during the health fair; develop suitable care strategies, and finally disseminate their work with other colleagues and professionals.

Although providing care and utilizing information regarding care are available and can motivate students to conduct research, this type of learning opportunity in the current course design is not often applied as a teaching methodology. Thus, utilization of students acquiring evidence-based research information as part of teaching on the undergraduate baccalaureate program is important part of learning outcomes.

The purpose of the study is to describe the development of an innovative systematic clinical course integrating a community participatory experience and a beginning research process in an undergraduate baccalaureate nursing program. Specific objectives include: 1) address the process of community participatory practice in the health fair event and describe the activities in the provision of health related services for older adults and 2) development of students' capability to bridge practice into EBP research as learning outcomes.

\section{METHOD}

The development of innovative systematic clinical practice consists of three parts: preparation, implementation and research process as outcomes of learning. The process was conducted after the approval of the Institutional Review Board of the university. Preparation stage: The community was surveyed to identify available places to bring the student nurses for the health fair event. In collaboration with San Diego County, Aging and Independent Services, contacts were made with senior centers to schedule the health fair events.

The leadership of the centers on the identified venue for the health fair were contacted to determine the most desirable and appropriate health related topics for seniors who come for meals at the center. The topics were discussed with the community partners and the topics of 'prevention of fall risks' and 'blood pressure screening' were selected as requested by community partners; and the schedule of the health fair was confirmed. Based on the size and space in each health fair, available number of students was calculated. Students were asked to sign up if interested and they were told that bilingual students would be given preference to address the linguistic needs of ethnically diverse older adults. As a result, only part of the students participated in the health fair event.

Different assessment tools used by students in Care of Older Adult Clinical are included in the course syllabus: The Balance and Gait Assessment, ${ }^{[18]}$ Timed Up and Go (TUG), ${ }^{[19]}$ 
10-year Fracture Risk. ${ }^{[20]}$ It is important to note that these reliable, valid tools are commonly used not only in nursing, but also in physical therapy and medicine. These assessment tools were selected by the faculty members and discussed with students the value of using valid and reliable instruments. The three assessments together could explain the participants' stability and flexibility of balance, fall risks and anticipate injuries from falls. Blood Pressure screening and related information ${ }^{[21]}$ were also selected to obtain basic background information (age, gender, race, awareness of high blood pressure, and daily physical activity) on the seniors who participated. Based on using these tools, health educational materials and a report form were made for seniors who participated at the health fair.

The week of the health fair, all the students recruited for this event met to practice and role play the use of the tools to assess the seniors as well as plan for the logistics arrangement prior to the event.

Implementation stage: On the scheduled date, students were divided into groups for each assessment tool with one additional group of students, which was assigned recruiting the seniors and obtaining their background information. When potential participants showed interest, students explained what they would do and the purpose of the activity. Students performed screening services and reviewed educational materials with the seniors together. Each senior received their assessment scores on a paper to take to the doctor at their next visit as well as the health related educational materials. The raw assessment data was retained for the next step of student research.
Research process: At the end of the semester, an announcement was made to the class about participation in a scholarly research process that would include analysis of health fair outcomes information and findings. One group of students showed interest for analysis of the collected information and further research work. A faculty guided the student group for analysis, significance, findings, resource of presentation. As group work, the student group met 3-5 times with the faculty mentor. The guidance for research process included data management (data entering, cleaning and analyzing the data), selecting a topic of the data, literature review and development of significance, findings, and preparation for presentation in scholarly meetings. The group presented the results orally at the Annual Students Research Symposium at San Diego State University and a poster presentation at the Western Institute of Nursing conference. Students were asked to write a reflection through the EBP research process.

\section{RESULT}

This report is a description focusing on community participatory health fairs as a part of clinical course activities. A total of seven community health events occurred at three different places - two senior centers and a church, which was designated place for Annual Fall Prevention event by San Diego County. A total of 74 students and all clinical faculty were able to participate in the health fairs during a two year period.

In each event, between 5-21 students could have participated and served based on the scale of the event and space assigned for nursing students (see Table 1).

Table 1. Number of students participation on health fair and screening outcome $(\mathrm{N}=74)$

\begin{tabular}{|c|c|c|c|c|c|c|c|}
\hline \multirow[b]{2}{*}{ Year } & \multirow{2}{*}{$\begin{array}{l}\text { Number of } \\
\text { Events }\end{array}$} & \multirow{2}{*}{$\begin{array}{l}\text { Students } \\
\text { (n) }\end{array}$} & \multirow[b]{2}{*}{ Health Fair Place } & \multicolumn{4}{|c|}{ Assessment (n) } \\
\hline & & & & Background & $\begin{array}{l}\text { Fracture } \\
\text { Risks }\end{array}$ & $\begin{array}{l}\text { Balance } \\
\text { \& Gate }\end{array}$ & TUG \\
\hline Semester 1 & 3 & 17 & Senior Centers & 55 & 55 & 55 & 55 \\
\hline Semester 2 & 2 & 21 & Senior Center \& Housing & 35 & 31 & 30 & 30 \\
\hline Semester 3 & 1 & 21 & Senior Center & 60 & 16 & 42 & 42 \\
\hline Semester 4 & 1 & 15 & Senior Center & 51 & 45 & 38 & 38 \\
\hline Total & & 74 & & 201 & 147 & 165 & 165 \\
\hline
\end{tabular}

Note. TUG, Timed UP and Go

Bilingual students who went to the health fair were able to use their second languages including Spanish, Mandarin, Tagalog, Korean and Arabic. The students screened a total of 201 older adults including basic health and demographic information, all three or part of fall assessment: 147 older adults had the result of 10 year risk of any fracture and hip fracture; 165 had evaluation of Balance and Gait and Timed
Up and Go performance. Each result was provided and explained to the senior participants about the meaning and fall prevention strategies. One group of students participated in the process of data analysis, development of research process (significance, methods, findings and conclusion), and dissemination of the result in intramural and extramural research events. The students who participated the health fairs 
expressed, first, their own pride about being able to serve the community when the seniors appreciated the students work (education, assessment, individualized advice for health concerns); second, their personal satisfaction in learning as they increased critical thinking, connection and application of nursing in the real world; last, they felt they were privileged to go through all the process of research including data collection, analyses, interpretation of the results and disseminating the results in a professional research symposium, where the nursing students saw other students from different majors who didn't have such opportunities. Students recommended to increase the number of events to give an opportunity for other nursing students to experience community participation and apply their knowledge in research process.

\section{Discussion}

The emphasis on essential role of nurses in healthcare ${ }^{[22]}$ focuses on the provision of quality care, requires creative strategies in the undergraduate nursing program to bridge students clinical course experience into research and evidence based practice. Lack of opportunity to conduct research and appreciation of EBP may be deterrent to improve care outcomes. Thus, connecting research and EBP may produce better quality care and enhanced patient care outcomes.

This article introduced the development of systematic and innovative clinical course integrating community participatory experiences and research in a baccalaureate nursing program. The clinical course was developed to follow the Recommended Baccalaureate Competencies and Curricular Guidelines for the Nursing Care of Older Adults, ${ }^{[12]}$ which emphasized community participatory care experiences; Implement and monitor strategies to prevent risk and promote quality and safety with fall risks (Essentials II \& IV); and Valid and reliable assessment tools were used to guide nursing practice for older adults (Essentials II \& IX).

For older adults, falls are the most common accident inducing fractures and injury: One in four older Americans fall, and more than 3 million older adults visited emergency department due to falls each year; and 1 in 5 falls causes a serious injury. ${ }^{[23]}$ CDC guided health care providers in 3 steps - screen, review, and recommend. ${ }^{[23]}$ Our program adapted all three guidelines for older adults at the health fair.

As shown in Table 1, the number of students who participated in each fair increased from year 1 to year 2. As a team of community health fair along with other vendors and disciplines, there was a limited space that resulted in limited opportunity for nursing students. Later we offered our own health fair with several topics to provide nursing students more experiences with older adults through the services they provide. Several health screening topics were added that include nutrition, depression, blood pressure and fall risk as originally requested by the community organization.

A health fair to prevent fall episodes was an appropriate selection for the event for both nursing students and older adults. Through repeated practice, nursing students became more aware of the prevalence of falls and balance issues among older adults; improved their communication and technical skills; and developed cultural competencies interacting with diverse ethnic groups. This health fair experience improved students' learning outcomes that is consistent with the literature. ${ }^{[24,25]}$

Although discussed in class prior to the health fair event and instructors' guidance during the actual event, more student training in screening, data collection, and recording are needed to improve data gathering. Students also require more familiarity with the use of various instruments including the reliability and validity value as best proven evidence, while integrating their clinical experience in order to evaluate service received and outcomes. This can be a step toward EBP initiatives and research inquiry. Nursing administration needs to foster an environment conducive to research and EBP and to consider the utilization of the findings in teaching within the BSN program.

\section{Conclusion}

Nurses are doing more research and evidence-based initiatives in health care settings. The process of research and implementing evidence into clinical practice must start at the nursing baccalaureate program. Although, the process can be a daunting experience, with faculty mentorship, it can lead to desired learning outcomes for students and improved health care outcomes for patients.

There are many creative ways that students can undertake these challenges. This article focuses on community health services provided by students in gerontological nursing clinical. There is limited literature on whether nursing students are competent to manage a community event for health service and integrate learning opportunities at the same time. With systematic planning and organizing of the clinical experience, in this study the students were able to assume their individual responsibilities as expected. The role-playing of their assignment prior to the actual health fair event was highly effective and provided the students confidence of what to do during the event.

This study findings indicate 1) an organized clinical experience in community participatory events was an appropriate method to develop students' competency in knowledge, skills, attitudes and culture; 2) this is a good opportunity for 
the students to understand the target population's health issues in depth and within the broad scope in their community; and 3) when the course is organized and related projects are prepared in advance, students' outcome and performance in practice and learning can bridge EBP initiatives and research.

\section{IMPLICATIONS FOR NURSING EDUCATION}

Findings of this study are evidence that organized clinical preparation can develop students' appreciation of the value of EBP in quality improvement outcomes through research inquiry. The potential for this study may replicated in other clinical courses within the BSN program. Although this innovative strategy allows senior nursing students to participate in research by gathering data while doing clinical activities, the development and implementation of the clinical activities require tremendous faculty effort and passion to develop the students' competence in care practice and research work. Nursing administration needs to foster an environment conducive to research and EBP. The research analysis could be connected to a further step in the nursing curriculum such as a course providing official credit.

\section{ACKNOWLEDGEMENTS}

The authors expressed their appreciation to the nursing students and older adults participated in community health fairs.

\section{CONFlicts of InTEREST Disclosure}

The authors declare that there is no conflict of interest.

\section{REFERENCES}

[1] Conn VS. Nurse researchers begin as undergraduate students. Western Journal of Nursing Research. 2007; 29(3): 255-7. PMid:17420519 https ://doi .org/10.1177/01939459062976 20

[2] Revell MA. Role of research in best practices. The Nursing Clinics of North America. 2015; 50(1): 19-32. PMid:25680484 https: //doi.org/10.1016/j.cnur.2014.10.002

[3] Stevens KR. The impact of evidence-based practice in nursing and the next big ideas. Online Journal of Issues in Nursing. 2013; 18(2): 4.

[4] August-Brady MM. Teaching undergraduate research from a process perspective. The Journal of Nursing Education. 2005; 44(11): 519-21. https://doi.org/10.3928/01484834-20051101-09

[5] Cepanec D, Clarke D, Plohman J, et al. Engaging undergraduate nursing students in research: the students' experience of a summer internship program pilot project. The Journal of Nursing Education. 2013; 52(8): 466-9. PMid:23855343 https://doi .org/10. 392 8/01484834-20130718-03

[6] Meeker MA, Jones JM, Flanagan NA. Teaching undergraduate nursing research from an evidence-based practice perspective. The Journal of Nursing Education. 2008; 47(8): 376-9. PMid:18751652 https://doi.org/10.3928/01484834-20080801-06

[7] Vessey JA, DeMarco RF. The undergraduate research fellows program: a unique model to promote engagement in research. Journal of Professional Nursing: Official Journal of the American Association of Colleges of Nursing. 2008; 24(6): 358-63. PMid:19022209 https://doi.org/10.1016/j.profnurs .2008.06.003

[8] Ryan EJ. Undergraduate nursing students' attitudes and use of research and evidence-based practice - an integrative literature review. Journal of Clinical Nursing. 2016; 25(11-12): 1548-56. PMid:26990808 https://doi.org/10.1111/jocn. 13229

[9] Smith CR, Martsolf DS, Draucker CB, et al. Stimulating Research Interest and Ambitions in Undergraduate Nursing Students: The Research-Doctorate Pipeline Initiative. The Journal of Nursing education. 2016; 55(3): 133-40. PMid:26926213 https ://doi.org/ $10.3928 / 01484834-20160216-03$

Published by Sciedu Press
[10] American Association of Colleges of Nursing. The Essentials of Baccalaureate Education for Professional Nursing Practice. In: AACN, editor. Washington D.C.: AACN; 2008.

[11] Council on Undergraduate Research (COUR). Characteristics of Excellence in Undergraduate Research. Washington, DC: COUR; 2012.

[12] American Association of Colleges of Nursing. Baccalaureate programs: The Essentials of Baccalaureate Education for Professional Nursing Practice. In: AACN, editor. Wachington D.C.: AACN; 2008.

[13] Begley K, Haddad AR, Christensen C, et al. A health education program for underserved community youth led by health professions students. American Journal of Pharmaceutical Education. 2009; 73(6): 98. PMid:19885067 https://doi .org/10.5688/aj730698

[14] Kosta J. Monitoring student attendance, participation, and performance improvement: an instrument and forms. Nurse Educator. 2012; 37(3): 115-20. PMid:22513770 https://doi.org/10.1097/NNE. Ob013e3182504171

[15] Leonard LG. Primary Health Care and partnerships: collaboration of a community agency, health department, and university nursing program. The Journal of Nursing Education. 1998; 37(3): 144-8.

[16] Maltby H. Use of health fairs to develop public health nursing competencies. Public Health Nursing (Boston, Mass). 2006; 23(2): 183-9. PMid:16684193 https://doi .org/10.1111/j.1525-1446.20 $06.230210 . x$

[17] Oelofsen N. Using reflective practice in frontline nursing. Nursing Times. 2012; 108(24): 22-4.

[18] Tinetti ME, Williams TF, Mayewski R. Fall risk index for elderly patients based on number of chronic disabilities. The American Journal of Medicine. 1986; 80(3): 429-34. https://doi.org/10.1016/ 0002-9343(86) 90717-5

[19] Podsiadlo D, Richardson S. The timed "Up \& Go": a test of basic functional mobility for frail elderly persons. Journal of the American Geriatrics Society. 1991; 39(2): 142-8. PMid:1991946 https://doi.org/10.1111/j.1532-5415.1991.tb01616.x

[20] FORE. The FORE 10-Year Fracture Risk Calculator (FRC). Foundation for Osteoporosis Research and Education http://riskcalcul ator.fore. org2010 [http://riskcalculator.fore.org] .

[21] Lee YS. Awareness of blood pressure among older adults: A crosssectional descriptive study. International Journal of Nursing Studies. 2006; 43(4). 
[22] Institute of Medicine (IOM). The Future of Nursing: Leading Change, Advancing Health. Washington (DC): National Academies Press (US); 2011. Available from: https://nationalrncm.com/wp-c ontent/uploads/2016/08/12956.pdf

[23] CDC. Fact Sheet: Falls Are a Major Threat for Your Patients: CDC; 2017 [cited 2018]. Available from: https://www.ncoa.org/news/resources-for-reporte rs/get-the-facts/falls-prevention-facts/
[24] Barba BE, Gendler P. Education/community collaborations for undergraduate nursing gerontological clinical experiences. Journal of Professional Nursing: Official Journal of the American Association of Colleges of Nursing. 2006; 22(2): 107-11. PMid: 16564476 https://doi.org/10.1016/j.profnurs .2006.01.008

[25] Thomas MH, Smith RS. Building community engagement: Incorporation of service learning in a nursing curriculum. Nurse Education Today. 2017; 52: 63-5. PMid:28267628 https://doi.org/10.1 016/j.nedt. 2017.01 .013 